\title{
AVALIAÇÃO DA APRENDIZAGEM NO CURSO DE NUTRIÇÃO
}

KÉLIN SCHWARZ PRISCILLA CAMPIOLO MANESCO PAIXÃO

\section{RESUMO}

O estudo objetivou investigar as concepções de avaliação da aprendizagem da forma como são percebidas por alunos e professores do curso de Nutrição de uma universidade pública do Paraná, bem como outras questões importantes referentes às práticas avaliativas. 0 estudo foi realizado por meio de questionários aplicados a professores e alunos, e as respostas foram agrupadas para a análise. Os resultados revelaram que a concepção de avaliação da aprendizagem para grande parte de alunos e professores foi semelhante e caracteriza-se como um instrumento para verificar o que o aluno assimilou. A prova foi o instrumento avaliativo relatado como o mais utilizado por todos os professores pesquisados, sendo geralmente associado a outros instrumentos avaliativos. Assim, enfatizam-se a necessidade e a importância de se repensar constantemente o significado da avaliação da aprendizagem, além da necessidade de capacitar continuamente professores e gestores do ensino superior, para que a avaliação realmente contribua para construção do conhecimento. 


\section{RESUMEN}

El presente estudio investigó cómo alumnos y profesores de un curso de nutrición en una universidad pública de Paraná perciben las concepciones de evaluación del aprendizaje. También se investigaron otras cuestiones importantes referentes a las prácticas de evaluación. El estudio se realizó a través de cuestionarios a profesores y alumnos y las respuestas fueron agrupadas para el análisis. Los resultados revelaron que la concepción de evaluación del aprendizaje fue similar para la mayoría de los alumnos y de los profesores, que la caracterizan como un instrumento para verificar lo que el alumno ha asimilado. Para los profesores encuestados, la prueba fue el instrumento de evaluación más utilizado, siendo asociada, generalmente, a otros instrumentos de evaluación. Así, se hace hincapié en la necesidad y la importancia de repensar constantemente el significado de la evaluación del aprendizaje, además de la necesidad de capacitar continuamente a profesores y gestores de la enseñanza superior para que la evaluación realmente contribuya en la construcción del conocimiento.

PALABRAS CLAVE EVALUACIÓN DEL APRENDIZAJE • PROCESO DE ENSEÑANZA-APRENDIZAJE • ENSEÑANZA SUPERIOR.

\section{ABSTRACT}

This study aimed at investigating the learning evaluation conceptions as they are perceived by students and lecturers at the Nutrition Course of a public university in the state of Paraná, as well as other important issues relating to evaluation practices. The study was conducted through questionnaires submitted to teachers and students, and the answers were grouped for analysis. The results revealed that the concept of learning evaluation was similar for most students and lecturers, and is characterized as a tool to verify what the student has assimilated. A test was the evaluation tool mostly used by all teachers, usually associated with other evaluative tools. Thus, we emphasize the need and importance constantly the meaning of learning evaluation in addition to continuously training higher education level teachers and administrators, so learning evaluation will effectively contribute to knowledge building. 


\section{INTRODUÇÃO}

O papel da avaliação no processo ensino-aprendizagem é motivo de estudos há algum tempo, mas é também uma das maiores dificuldades encontradas no campo educacional da atualidade (LINN, 1993; FARIA, 2011).

A complexidade dos fatores envolvidos no processo de avaliação da aprendizagem indica que não existe uma única concepção de avaliação, mas diferentes formas possíveis de abordar o ato de avaliar (ALMEIDA; PERON; SILVA, 2009), as quais possuem implicações pedagógicas que vão além dos aspectos técnicos e metodológicos, alcançando aspectos sociais, éticos e psicológicos. Dessa forma, as práticas avaliativas podem estimular, promover avanços e crescimento, mas podem também desestimular, frustrar e impedir o crescimento dos sujeitos (BERBEL et al., 2000).

As diferentes formas de avaliar devem ser compatíveis com os paradigmas educacionais emergentes, ou seja, uma avaliação orientada para a aquisição de competências, buscando o desenvolvimento do pensamento crítico e reflexivo dos estudantes (GONÇALVES, 2008; VASCONCELLOS, 1998). Isso implica 
repensar de modo amplo os diversos aspectos do processo de ensino e aprendizagem, incluindo as práticas de avaliação que são utilizadas no ensino universitário (GARCIA, 2009).

Nesse sentido, Perrenoud (1999, p. 38) afirma que "a função nuclear da avaliação é ajudar o aluno a aprender e ao professor a ensinar", determinando também quanto e em que nível os objetivos estão sendo atingidos, devendo a avaliação do processo de aprendizagem pautar-se pelas funções: conhecer melhor o aluno (suas competências curriculares, seu modo de aprendizagem, seus interesses, suas técnicas de trabalho); constatar o que está sendo aprendido; adequar o processo de ensino aos alunos como grupo e àqueles que apresentam dificuldades, tendo em vista os objetivos propostos, bem como procurando apreciar globalmente o processo ensino-aprendizagem.

A Lei de Diretrizes e Bases da Educação Nacional (LDBEN), Lei n. 9394/96 (BRASIL, 1997), determina que a avaliação da aprendizagem deva ser cumulativa e contínua, enfatizando que o desempenho geral do educando deve ter maior peso que as provas finais e que os aspectos qualitativos devem prevalecer sobre os quantitativos. Assim, entende-se que a avaliação ultrapassa a mera relação entre o ensinado e os resultados obtidos, para que, numa perspectiva sistêmica de análise, o foco principal esteja direcionado para aquilo que o aluno aprendeu e o uso que faz dessas aprendizagens (GONÇALVES, 2008).

Entretanto, o que se observa nas avaliações de aprendizagem nas instituições de ensino não é exatamente essa prática, mas uma avaliação na qual as notas são usadas para fundamentar necessidades de classificação de alunos. Para esta são comparados os desempenhos e não os objetivos que se deseja atingir (LUCKESI, 2002).

O que ocorre é que grande parte dos professores universitários têm dado pouca relevância à sua preparação para a função de ensino, pois estão firmados na ideia de que o professor universitário se caracteriza como um especialista no seu campo de conhecimento, ou seja, para o ensino superior, o mais importante é o domínio dos conhecimentos referentes à sua área de atuação, enquanto a formação didática não é necessária, porque os alunos universitários, por serem adultos e por estarem motivados pela profissionalização ao final 
do curso, estão, a priori, preparados para aprender sozinhos (ROZENDO et al., 1999; ABREU; MASETTO, 1997).

Na área da saúde não é diferente: os profissionais que atuam como professores universitários geralmente optam por programas de pós-graduação em suas áreas de formação específica devido a maior valorização profissional pelas instituições de ensino superior e agências de fomento à pesquisa, deixando de lado a formação para a área educacional e pedagógica (GOMES; ORTEGA; OLIVEIRA, 2010).

Conhecendo os diferentes entendimentos sobre a avaliação do ensino-aprendizagem, percebe-se que a prática da avaliação da aprendizagem que vem sendo desenvolvida em muitas instituições de ensino não tem mostrado muitos avanços, no que tange à avaliação como um elemento auxiliador do processo ensino-aprendizagem. Ao contrário, a avaliação está sendo utilizada como mero elemento quantificador do conhecimento, deixando de identificar e estimular os potenciais dos estudantes.

Diante dessa realidade, é de grande importância conhecer as concepções dos professores e estudantes sobre a avaliação da aprendizagem, os instrumentos avaliativos utilizados e as dificuldades encontradas no ato de avaliar, já que por meio destas, pode-se repertoriar o processo de avaliação, de uma situação desfavorável à aprendizagem significativa, para um ambiente de produção positiva. Portanto, o objetivo deste trabalho é identificar as concepções e finalidades do processo de avaliação da aprendizagem para alunos e professores do curso de Nutrição de uma universidade no estado do Paraná.

\section{METODOLOGIA}

O estudo consiste em uma pesquisa de campo realizada com alunos e professores do curso de Nutrição de uma universidade do Paraná, após a aprovação do projeto de pesquisa pela Coordenação de Pós-Graduação em Docência no ensino superior do Centro Universitário de Maringá e a concordância na realização da pesquisa pelo departamento de Nutrição dessa instituição. 
Os instrumentos utilizados para a coleta de dados foram questionários elaborados pelos autores com perguntas abertas e fechadas, aplicados aos professores e alunos. Os alunos envolvidos na pesquisa correspondem ao $2^{\circ}, 3^{\circ}$ e $4^{\circ}$ anos do curso de Nutrição. Os alunos do $1^{\circ}$ ano não foram incluídos na pesquisa pelo fato de estarem ingressando no ensino superior nesse ano da pesquisa e, portanto, o contato com o processo avaliativo da referida universidade ainda é muito restrito.

O questionário dos professores, composto por 10 questões, e o dos alunos, por 7 (Anexo I e II), foram respondidos individualmente após esclarecimentos sobre a finalidade da pesquisa e a concordância em dela participar voluntariamente.

Para a análise dos dados qualitativos foram seguidas as orientações de Minayo (1992), as quais apontam para a organização dos dados, sua divisão em unidades ou categorias, um esforço de síntese, a procura por padrões e a identificação de aspectos importantes para a compreensão do tema que foi estudado. Os dados quantitativos foram analisados por meio da verificação de frequência, expressa em porcentagem.

\section{RESULTADOS E DISCUSSÃO}

Os sujeitos da pesquisa foram 9 professores, 6 do sexo feminino e 3 do sexo masculino, que ministram aulas no curso de Nutrição. Possuem graduação em Nutrição (77,8\%), Engenharia de Alimentos (11,1\%) e Matemática (11,1\%). Destes, 44,4\% têm doutorado, 44,4\% mestrado e $11,1 \%$ especialização. A maioria ministra aulas há mais de 10 anos na instituição referida e é responsável por uma ou até quatro disciplinas no curso de Nutrição. Cerca de $44,4 \%$ têm idade entre 25 e 30 anos; $11,1 \%$, entre 30 e 40, e 44,4\%, mais de 40 anos.

Os alunos participantes da pesquisa foram 82 , sendo $28 \%$ do $4^{\circ}$ ano do curso, $30,5 \%$ do $3^{\circ}$ ano, e $41,5 \%$ do $2^{\circ}$ ano. A maior parte dos alunosédosexofeminino(96,3\%)e 57,4\%têmentre17e20anos;36,8\% entre 20 e 25 anos; $2,9 \%$ entre 25 e 30 anos; e 2,9\% entre 30 e 40 anos.

A análise das respostas dos alunos a respeito da primeira questão "explique o que você entende por avaliação da aprendizagem" revelou opiniões que puderam ser divididas em três categorias: 1. Verificar o aprendizado/desempenho do aluno; 2 . 
Relação da avaliação com provas, trabalhos e notas; 3. Avaliar tanto aluno quanto professor.

Grande parte das respostas dos alunos se inseriu na primeira categoria "verificar o aprendizado/desempenho do aluno", ou seja, a avaliação, de acordo com eles, é o que o aluno aprende de algum conteúdo, como ilustrado por algumas das respostas obtidas:

Método utilizado para verificar o nível de aprendizagem dos alunos.

Um método para avaliar o que o aluno absorve das informações repassadas pelos professores.

Maneiras e métodos para avaliar o conhecimento obtido em determinado assunto.

É uma avaliação para verem se estamos aprendendo e entendendo bem a matéria e se estamos absorvendo os conhecimentos.

A segunda categoria de respostas "avaliação são provas, trabalhos e notas" pode ser constatada com base em respostas como as que seguem:

É a avaliação (prova) aplicada pelos professores para ver o desempenho e o grau de aprendizagem dos alunos sobre um determinado tema.

É a maneira que os professores utilizam para atribuir notas aos alunos em relação ao conhecimento repassado por eles.

Saber quanto o aluno aprendeu em determinado assunto por meio de provas e seminários.

Entender o que a pessoa sabe ou não, a partir de um trabalho, prova, etc.

Mostrar o que aprendeu através de uma avaliação (prova).

E a terceira categoria, "avaliar tanto aluno quanto professor", mostra respostas com uma visão de mão dupla, ou seja, avaliar tanto o professor quanto o aluno, tanto a aprendizagem quanto o ensino. Nessa avaliação é verificada se a forma como o professor ensina está contribuindo para o aprendizado e se o aluno dá o feedback ao professor, como se pode observar em alguns exemplos das respostas a seguir: 
Avaliação da aprendizagem é quando se aplica algo para ver se o aluno aprendeu e se o professor ensinou de forma correta. Não necessariamente em forma de provas e trabalhos, pode ser em um diálogo no momento do estudo, entre outros.

São instrumentos usados para avaliar o conhecimento adquirido perante o conhecimento transmitido: professor-acadêmico.

Uma forma de o professor avaliar se seus métodos de ensino estão sendo apropriados e se seus alunos estão entendendo o conteúdo.

Monitorar desempenho do aluno e professor.

É uma maneira, tanto de alunos quanto de professores, saberem o quanto é aproveitado daquilo que é apresentado em sala.

Em relação a esta mesma questão "explique o que você entende por avaliação da aprendizagem", as respostas dos professores puderam ser representadas em dois grupos: o primeiro grupo, com maior participação, conceitua a avaliação como verificação do aprendizado; o segundo associa a avaliação ao resultado da aula, um retorno ao educador. Os professores que conceituaram avaliação como "verificação do aprendizado" a associam ao conteúdo ensinado:

Avaliação é medir, quantificar o conhecimento ensinado.

Forma de avaliar o conhecimento adquirido pelos alunos.

Todo processo ou método que visa reconhecer a retenção por parte dos alunos daquilo que thes foi ensinado, após aulas ou outros métodos de transmissão de conhecimento.

É um método para verificar se o aluno aprendeu ou não os conteúdos ministrados.

As ideias dos professores que conceituaram a avaliação como "resultado da aula" estão ilustradas a seguir:

São formas e métodos de retorno ao educador sobre os conteúdos trabalhados. 
É o resultado, seja negativo ou positivo da aula prática/teórica.

Diante das respostas a respeito do que é avaliação da aprendizagem, palavras como "transmissão deconhecimento" e "informações repassadas" evidenciam que ainda existe a ideia do professor comotransmissor do conhecimento e oaluno como simples receptor. Esse pensamento está presente tanto na fala de alunos quanto de professores, demonstrando que certos conceitos e formas deeducação permanecem enraizados na universidade. Atrelado a isso, as respostas analisadas apontaram que a maior parte dos alunos e professores do curso de Nutrição entende que a avaliação é verificar se o aluno aprendeu o conteúdo, geralmente associando essa verificação a provas e notas. Para Hoffmann (1991, p. 14),

A concepção de avaliação que marca a trajetória de alunos e educadores, até então, é a que define essa ação como julgamento de valor dos resultados alcançados. Daí, a presença significativa dos elementos como prova, nota, conceito, reprovação, registro etc. nas relações estabelecidas.

É interessante, também, observar que nenhum professor se referiu à avaliação como um processo contínuo, ou seja, a avaliação da aprendizagem não é vista como um suporte constante ao processo de ensino e aprendizagem, mas como uma ferramenta que pode ser utilizada em determinados momentos para "verificar a aprendizagem do aluno". A respeito da avaliação da aprendizagem, Furlan (2006, p. 28) afirma que:

[...] pode ser definida como um meio de obter informações sobre os avanços e as dificuldades dos alunos, constituindo um procedimento permanente de suporte ao processo ensino e aprendizagem, de orientação para o professor planejar suas ações, a fim de conseguir ajudar o aluno a prosseguir, com êxito, seu processo de educação.

Essa visão abrangente de avaliação da aprendizagem não foi identificada pelos sujeitos pesquisados, entretanto alguns deles percebem que a avaliação tem relação tanto com o aluno como com o professor. Isso pode ser um primeiro passo para que a avaliação da aprendizagem seja compreendida como um instrumento capaz de auxiliar o desenvolvimento cognitivo dos alunos e pautar a ação docente. 
Em relação aos instrumentos avaliativos, os professores em sua unanimidade relataram fazer uso da "prova escrita", geralmente associada a um ou mais instrumentos, como seminários, trabalhos em sala de aula, relatórios de aulas práticas, estudos de caso, estudos dirigidos, resenhas, participação em sala de aula e presença. Alguns até percebem que existem falhas em determinados instrumentos:

As provas da forma como são não são comprovantes eficazes, a prática demonstra muito mais a aprendizagem.

$\mathrm{Na}$ instituição em questão, o regimento geral determina que a avaliação da aprendizagem nos cursos de graduação deve ser específica para a área e definida no Projeto Político Pedagógico, cabendo ao professor propor as formas, os critérios e os instrumentos de avaliação quando da elaboração do plano de ensino, mostrando que a prova não é um instrumento imposto pela instituição.

Os alunos também foram unânimes quando relataram o instrumento de avaliação "prova" como o mais utilizado pelos professores. Mas, nas respostas, o instrumento prova também sempre esteve aliado a outros, como seminários, trabalhos, estudos de caso, pesquisas, aulas práticas, estudo de artigos científicos, relatórios e presença. E, quando questionados a respeito da eficiência dos instrumentos avaliativos utilizados por seus professores, a maior parte dos alunos $(52,9 \%)$ considerou os instrumentos eficientes, como evidenciado a seguir em resposta à questão "você considera os métodos e instrumentos utilizados por seus professores como eficientes para sua aprendizagem?":

Sim, pois para conseguir fazê-los temos que estudar, prestar atenção nas aulas, desta forma aumentam nossos conhecimentos, sendo eficaz o aprendizado.

Sim, pois a maioria dos professores utiliza mais de um método avaliativo e é isso que considero importante.

Sim, principalmente os trabalhos mais voltados para a prática, como elaboração de manuais e estudos de caso.

Sim, pois com as provas o aluno tem o compromisso de estudar. 
Sim, porque faz com que eu me esforce para ter um desempenho bom nas provas.

Outra parte dos alunos $(47,1 \%)$ respondeu que nem sempre os instrumentos utilizados são eficazes, depende do instrumento e do professor que os aplica, como demonstram as respostas:

As apresentações sim são eficazes, mas provas escritas não são tão eficientes. No dia da prova o aluno pode estar com problemas de saúde ou psicológicos e isso interferir no desempenho.

Depende, em relação às provas, no meu ponto de vista intimida muito o aluno, que muitas vezes tem uma capacidade muito maior do que aparenta ao realizar uma prova.

Em alguns casos não, pois prova acaba sendo forma de decorar, assim não há aprendizado.

Não muito. Para as provas não estudamos e sim decoramos, já para os trabalhos estudamos, pois quando estamos fazendo ou montando, estamos estudando.

Alguns métodos sim. Alguns professores, ao preparar uma prova, se focam muito na teoria, ou seja, exigem do aluno algo decorado, o aluno tem que saber a ordem das palavras na frase e não consideram sinônimos.

Com isso, percebe-se que a palavra "prova" apareceu com grande frequência, tanto nas respostas dos alunos quanto nas dos professores, revelando que no curso de Nutrição os alunos são predominantemente avaliados por provas e também que há forte relação entre prova e avaliação, ou seja, fazer uma prova e dar uma nota é avaliar, assim como evidenciado por Augusto (2001) quando pesquisou alunos e professores do curso de Física de uma universidade em São Paulo. Além disso, a prova é uma prática bastante antiga e tradicional, então é natural que alunos e professores, ao falarem de avaliação, falem de provas (CAMARGO, 1996).

Entretanto, como os próprios alunos afirmaram, nem sempre a prova é o melhor método de avaliar. Alguns a consideraram 
como forma de pressão, já que, ao saber que haverá prova, se "obrigarão" a estudar, mas outros entendem a prova como instrumento que intimida e que, muitas vezes, exige a memorização por parte do aluno para garantir uma "boa nota", mas como os próprios alunos descreveram a simples memorização de informações não é garantia de aprendizagem. Ainda, por diversas vezes, a avaliação pode gerar tanta tensão nos alunos que eles acabam deixando de ser espontâneos e criativos e, por isso, não conseguem mostrar aquilo que realmente sabem (SOUZA, 1994).

Um ponto positivo que se pode notar é que a prova, apesar de ser o instrumento mais utilizado, geralmente esteve acompanhada de outros instrumentos, citados tanto por alunos quanto por professores, indicando que há uma variação dos instrumentos utilizados. A variação nos instrumentos é importante, pois, de acordo com Souza (1994), um único tipo de avaliação pode não possibilitar uma visão do verdadeiro desempenho dos estudantes, uma vez que atividades diversas, como seminários, trabalhos, permitem ao professor conhecer como os alunos se saem em diferentes propostas de trabalho, possibilitando avaliar os alunos de forma global, afinal estes são diferentes uns dos outros e também têm diferentes desempenhos em determinadas tarefas.

Além disso, a utilização de outros tipos de avaliação proporciona aos alunos lidarem com diferentes situações, o que contribui para que eles se tornem ainda mais aprendizes independentes e que, na vida profissional, estejam preparados para as mais diversas situações. Isso se torna ainda mais importante na sociedade em que vivemos, na qual as mudanças sociais e tecnológicas são muitas, as informações são modificadas a todo momento e os conhecimentos são constantemente atualizados (GODOY, 1995).

Ainda em relação à questão "você considera os métodos e instrumentos utilizados por seus professores eficientes para sua aprendizagem?”, dos 47,1\% que consideraram alguns instrumentos bons e outros não, diversas vezes os "seminários" foram citados pelos alunos nas respostas mas, assim como a prova, esse instrumento divide opiniões. Vários alunos afirmaram que não julgam seminários um bom instrumento de avaliação, já outros o consideram eficiente: 
Nos seminários, os alunos dedicam-se apenas a seu trabalho, não se importam muito com o dos outros.

Seminários ficam pouco explicados, mas outros instrumentos são eficientes.

Em seminários, considero o aproveitamento baixo.

Apenas acho que os seminários deveriam acontecer em menor número, pois é mais difícil assimilar um conteúdo passado por outro colega, e ainda, este conteúdo ser de prova.

Métodos como provas e estudos de caso julgo eficientes por exigirem mais tempo de dedicação, dessa forma obtém-se a aprendizagem esperada. Já os seminários, muitas vezes são pouco entendidos devido à didática que cada um possui para apresentar.

Eu, particularmente aprendo quando é por seminários e o professor complementa o que faltou, e também acho a prova eficiente.

As insatisfações com os seminários provavelmente acontecem, pois estes, da maneira como são realizados pelos professores, bem como pela forma como são encarados pelos próprios alunos, não auxiliam na aprendizagem e avaliação, talvez por desconhecimento da real estratégia “seminário", que é composta por dois momentos, um de pesquisa científica e outro de mesa-redonda, ambos coordenados pelo professor de forma a construir o conhecimento coletivo (MASETTO, 2001). O que muitas vezes ocorre é somente a distribuição de temas para os grupos, estes dividem o tema entre seus membros para a apresentação, cada um apresenta sua parte, sem conhecimento da parte do outro componente e, muitas vezes, sem a preocupação de fazer uma boa pesquisa e uma boa apresentação, de forma que seus colegas não mostram interesse pelo assunto, e o professor não o retoma, pois se retomar não conseguirá "vencer o conteúdo". Vale ressaltar que a técnica do seminário não deve substituir a abordagem teórica do professor, como também o conhecimento da técnica por parte dos professores faz toda a diferença.

Nesse sentido, a respeito da formação dos professores (graduação ou pós-graduação), questionou-se se em algum 
momento de sua formação puderam participar de alguma disciplina relacionada à avaliação da aprendizagem. Dos professores participantes da pesquisa, 55,5\% relataram não ter nenhuma disciplina relacionada à avaliação durante sua formação, afirmando que aprenderam a avaliar no decorrer dos anos, com a prática profissional ou então buscando na literatura, como ilustrado a seguir:

Pelo conhecimento adquirido durante o trabalho ao longo dos anos, buscando a melhor forma de avaliá-los. Conhecendo cada turma se torna mais fácil.

Prática e experiência no dia a dia de trabalho. Acho importante conhecer cada aluno para poder avaliá-lo.

Buscando na literatura especializada exemplos e soluções para melhor avaliar o aluno.

Já os professores que relataram ter a disciplina Avaliação em algum momento de sua formação $(45,5 \%)$ alegaram que a disciplina influenciou positivamente na prática pedagógica como um todo, inclusive para a prática da avaliação.

Com isso, percebe-se que a maioria dos professores do curso de Nutrição da instituição em questão não teve, em sua formação, o preparo para a docência, o que implica não em dizer que o professor não sabe como avaliar, apenas que se houvesse o conhecimento didático-pedagógico aprimorado, talvez, alunos, professores e a própria instituição obtivessem maior êxito no processo de ensino-aprendizagem. Entretanto, a falta de disciplinas relacionadas à docência na formação de professores do ensino superior ocorre em diversas outras instituições de ensino superior e em diversos outros cursos. Em geral, apenas os professores oriundos das licenciaturas é que possuem em seus currículos uma ou duas disciplinas didático-pedagógicas (BERBEL et al., 2000). Ao mesmo tempo, as dificuldades na avaliação, provavelmente, são maiores para os docentes que atuam no ensino superior em relação aos que atuam nos demais níveis, porque os alunos são mais maduros, têm clareza do que querem, preparam-se para uma profissão. Dessa forma, é preciso entender que as ações dos professores têm consequências na relação com seus alunos, na relação destes e de ambos com 
o conhecimento e com as situações de vida que enfrentam no seu dia a dia (BERBEL et al., 2000).

Ainda, cabe ressaltar que a forma como o professor ensina e os critérios de avaliação que utiliza são consequência de sua formação, das condições de trabalho que lhes são dadas, da concepção que tem de sociedade, educação, ensino e avaliação (FALCÃO FILHO, 1995). Essas ideias corroboram com Luckesi (2002), que afirma que as práticas do professor são dimensionadas por um modelo teórico de mundo e de educação, traduzido em prática pedagógica, tenha o professor consciência disso ou não.

Para Casagrande, Macedo e Machado (2006), o professor competente deve conhecer os diferentes instrumentos para avaliação, saber a melhor forma de utilizá-los, além de ter o entendimento de que a avaliação não é um instrumento de pressão para manter a disciplina em sala de aula ou para fazer o aluno estudar. Se optar pelo uso de provas, o professor competente deve também desenvolver a habilidade de elaborar essas provas, de forma a avaliar os alunos o mais corretamente possível. Entenda-se habilidade em elaborar uma prova como habilidade para contextualizar a prova de acordo com os objetivos estabelecidos, com perguntas claras e precisas e que questionem apenas conteúdos relevantes.

Nesse sentido, fica clara a necessidade de investir na formação e atualização do professor no que diz respeito aos aspectos pedagógicos de seu trabalho, além da atualização em conteúdos específicos de sua área, melhorando, desse modo, sua competência profissional e o processo de ensino-aprendizagem.

Quanto às atitudes tomadas diante dos resultados das avaliações dos alunos, podem-se identificar duas categorias. A primeira categoria englobou grande parte das respostas dos professores, que afirmavam realizar a correção dos instrumentos de avaliação em conjunto com os alunos:

Faço correção conjunta de provas e relatórios e verifico porcentagem de notas baixas.

Verifico o aproveitamento dos alunos, resolvo a avaliação e faço uma discussão com os alunos sobre o resultado.

Peço para que os alunos façam a conferência das notas e correções. Em seguida, faço as correções juntamente com eles na tentativa de tirar dúvidas. 
Na segunda categoria de respostas, os professores relataram a preocupação com os erros cometidos pelos alunos:

Tenho maior atenção com os alunos que apresentam baixo desempenho.

Retorno a eles os pontos positivos e negativos, buscando meios de melhorar os pontos que não foram compreendidos e fixados.

Apresento os resultados, discuto os principais erros e alerto para as próximas avaliações.

Já os questionamentos feitos aos alunos a respeito das atitudes de seus professores diante dos resultados das avaliações demonstraram respostas que puderam ser divididas em quatro categorias: 1. Professores que auxiliam alunos que obtiveram baixo desempenho com trabalhos extras; 2. Professores que, dependendo do resultado, modificam métodos e instrumentos; 3. Professores que discutem a avaliação e tiram dúvidas e; 4. Professores que somente passam o resultado (a nota).

A primeira categoria, identificada de acordo com as respostas dos alunos, enquadra aqueles professores que, diante de resultados não tão bons de avaliações, ou seja, de notas baixas, auxiliam o "aumento" da nota com trabalhos extras:

Quando os resultados são muito ruins, os professores procuram dar algum trabalho para melhorar a nota.

Tentam ajudar quem não obteve um resultado muito bom, dando alguns trabalhinhos.

Se há notas abaixo do esperado, normalmente eles conversam com a turma para ver o que está errado, às vezes ajudam com trabalhos para melhorar a nota.

Conforme a nota atingida, contribuem para que seja possível uma recuperação.

O segundo grupo de respostas aponta para professores que modificam seus métodos e instrumentos de avaliação dependendo do resultado destes, conforme ilustrado a seguir:

Bons resultados mantêm as avaliações, maus resultados mudam o jeito de avaliar. 
Se os resultados são positivos, os professores se sentem satisfeitos e dão segmento a sua conduta. Se os resultados são negativos procuram mudar seu método de ensino.

Alguns tentam conversar para saber o motivo de tantas pessoas irem mal, tentam mudar o método de avaliação.

A terceira categoria identificada nas respostas diz respeito aos professores que discutem as avaliações em função dos resultados e esclarecem possíveis dúvidas e até mesmo retomam pontos importantes de algum conteúdo:

Alguns professores repassam as notas e discutem [...].

Alguns professores entregam as questões e debatem, outros entregam e dão a liberdade para tirar dúvidas e conversar.

Alguns revisam mais uma vez o conteúdo se o aluno não aprendeu [...].

E, por último, identificou-se a categoria de respostas que diz que os professores não tomam nenhuma atitude diante dos resultados das avaliações, apenas repassam as notas, como ilustrado nas respostas a seguir:

$\mathrm{Na}$ maioria das vezes não tomam atitude nenhuma.

Dependendo do resultado da turma, ele [o professor] deveria se reavaliar, mas não é necessariamente o que acontece, muitos não estão nem aí para os alunos.

Alguns professores apenas falam ou mandam por e-mail os resultados e, se o aluno quer revisar a prova, ele tem que ir até o professor, fora do horário de aula.

Alguns professores apenas repassam as notas e outros nem chegam a repassar.

Nota-se que os alunos descreveram de forma um pouco diferente aquilo que os professores também puderam relatar. Entretanto, é preciso compreender que os alunos responderam pensando em todos os professores com os quais têm aulas, enquanto somente nove professores que ministram aulas no 
curso de Nutrição puderam ser pesquisados, ou seja, não foi possível verificar a prática de todos os professores com relação aos resultados da avaliação. Dessa forma, é possível entender a diferença encontrada.

Com base nas respostas obtidas, tanto de professores quanto de alunos, foi possível perceber uma grande preocupação com a "nota” atribuída às avaliações. Nestas frases: “se o resultado foi ruim”, "maus resultados”, "resultados negativos", os resultados ruins, negativos, maus referem-se às notas baixas. Alguns professores se preocupam em retomar o conteúdo quando se deparam com esses resultados, tentam tirar dúvidas, outros auxiliam dando trabalhos extras para melhorar a nota e outros, simplesmente, repassam as notas e as registram.

Entretanto, valorizar a nota alta e se preocupar com a nota baixa não é o problema em si. O problema é quando a preocupação, tanto por parte dos alunos quanto dos professores, passa a ser só com a nota, e a aprendizagem, que deve ser a prioridade, acaba sendo deixada de lado. Se a nota assume maior importância para os professores, consequentemente assim o será para os alunos (AUGUSTO, 2001) e, quem sabe, a pressão que sentirão em relação às notas os atrapalhará ao realizar uma prova ou apresentar um trabalho. Além disso, a ausência de diálogo entre professores e alunos, seja sobre o resultado da avaliação, sobre o conteúdo, o que pensam sobre como são avaliados, seja sobre informações a respeito de sua aprendizagem, também interfere na avaliação (AUGUSTO, 2001).

A respeito do diálogo, parece evidente que os alunos do curso de Nutrição gostariam que todos os professores fossem abertos ao diálogo e proporcionassem um feedback de sua aprendizagem, não somente quanto às notas, mas também com relação à qualidade do seu desempenho e aos passos no processo de aprendizagem.

A importância do feedback reside no fato de que ele gera uma conscientização, com base na descrição e discussão do desempenho em determinada situação ou atividade, pois destaca as dissonâncias entre o resultado pretendido e o real, incentivando a mudança ou então motivando o indivíduo a repetir o acerto (COLLINS, 2004). Consequentemente, a habilidade de dar e receber feedback melhora a aprendizagem. 
Há ainda a preocupação com aqueles professores que não tomam atitude nenhuma diante dos resultados e, portanto, não entendem o real sentido da avaliação, ou seja, compreender e refletir sobre o estágio de aprendizagem do aluno, para poder avançar em seus conhecimentos e continuar o processo. Nesse caso, os professores "verificaram a aprendizagem dos alunos", assumiram uma nota para essa aprendizagem, mas não fizeram com que o aluno entendesse seus erros para que não os cometesse mais, nem lhe trouxeram novas informações e, por fim, nem lhe ajudaram a crescer na aprendizagem.

Em relação a como gostariam de ser avaliados, as respostas dos alunos foram bastante distintas: $11,8 \%$ dos alunos preferem ser avaliados por provas e trabalhos (trabalhos incluem seminários, estudos de caso, em sala de aula etc.); já 17,6\% preferem ser avaliados somente por provas, pois, como dito por eles mesmos, essa modalidade de avaliação os "obriga a estudar", e isso foi considerado importante para o aprendizado para esses alunos; $20,6 \%$ dos alunos gostariam de ser avaliados somente por trabalhos; $16,2 \%$ acreditam que assim como são avaliados está bom; e 33,8\% gostariam de ser avaliados de outras maneiras, que incluem ou não provas e trabalhos. Essas outras maneiras são exemplificadas em algumas das respostas a seguir:

Gostaria de ser avaliado sem precisar decorar o conteúdo, mas aprendê-lo como um todo.

Ser avaliado pelo esforço e participação dentro de sala de aula, pois às vezes as notas de provas e trabalhos não são o que realmente a pessoa merece.

Gostaria de mais abordagens práticas além de teóricas.

Além de provas e trabalhos, a conduta dos alunos em sala de aula deveria ser avaliada.

Pelo interesse, provas e leituras além do cobrado em sala de aula.

Com base nessas respostas, percebe-se que boa parte dos alunos gostaria de ser avaliado por mais de um instrumento, o que de fato ocorre, pensando nas respostas já analisadas de professores e alunos, mas, além disso, os alunos citaram 
"avaliação do interesse", "avaliação do esforço", "sem decorar conteúdo”, ou seja, os alunos sentem falta de diferentes formas de avaliação. Mas a avaliação da qual eles sentem falta é aquela que necessita de diálogo para ser efetivada, que necessita da aproximação entre aluno e professor, de forma que os professores reconheçam a dedicação, interesse e esforço do aluno. Talvez isso não aconteça justamente pelo fato de os professores estarem distantes dos alunos, por falta de interesse do professor para com as atividades do aluno ou, muitas vezes, em virtude do grande número de alunos que muitos professores têm. Apesar de ser uma tarefa difícil acompanhar as atividades dos alunos quando há um número muito grande deles, o estabelecimento de vínculos professor-aluno é fundamental para o processo ensino-aprendizagem, inclusive na universidade (HOFFMANN, 1991; GRIGOLI, 1990).

Mas, assim como há os alunos que gostariam de ser avaliados de formas diferentes das tradicionais, ou aliá-las a outras formas, há também os alunos que preferem que a avaliação continue como está, ou que as provas permaneçam, pois é assim que sempre foram avaliados e é assim que estão acostumados a fazer. Há certo comodismo por parte de alguns alunos, afinal é mais fácil decorar, não fazer relações, não forçar o pensamento, e há outros alunos que têm a necessidade da pressão, da obrigação de estudar para uma prova.

O comodismo, provavelmente, está presente, pois as mudanças são incertas, ou porque muitas vezes é mais fácil decorar para a prova, sem o compromisso de aprender. E estudar sob pressão nem sempre significa estudar e aprender, então, talvez por ser uma atividade tão enraizada, os alunos não consigam se libertar ou, às vezes, por imaturidade, precisam ter algo que os force a estudar, como, por exemplo, para a prova, algo que não fariam se esta não houvesse, mas alunos comprometidos com seu curso, que querem realmente aprender, não precisam de pressão para estudar.

Por outro lado, até que ponto a cultura da avaliação por provas que geram notas está enraizada em nossa sociedade? A responsabilidade por essa cultura não pode recair totalmente sobre os professores. Em observação realizada por Casagrande, Macedo e Machado (2006), a tentativa de implementar a avaliação formativa em uma turma de alunos do ensino médio em 
Florianópolis demonstrou que alguns conceitos estão muito enraizados e a mudança nem sempre é bem vista por alunos e professores, mesmo sabendo que poderá contribuir de forma significativa para o aprendizado. Os autores observaram que, ao tentar mudar os critérios de avaliação dos alunos, trocando as provas por trabalhos em sala (que poderiam ser avaliados individualmente), sem que estes tivessem notas de zero a dez, os alunos passaram a cobrar as notas, pressionando para que houvesse uma prova nos moldes a que eles estavam acostumados. Isso mostra que mudar a mentalidade da avaliação não é um processo simples e fácil, mesmo que os atores envolvidos no processo almejem essa mudança. Para Casagrande, Macedo e Machado (2006), o primeiro passo para a transformação é dar ao processo de avaliação um novo sentido, uma oportunidade para o aluno ler, refletir, relacionar, operar mentalmente e demonstrar que tem recursos para abordar situações complexas. Nesse sentido, é interessante mostrar aos alunos o quão importante pode ser o processo de aprendizado e quanto isso facilitaria seu entendimento sobre a reflexão de sua prática social.

\section{CONSIDERAÇÕES FINAIS}

As concepções e finalidades da avaliação da aprendizagem para alunos e professores foram semelhantes em diversos momentos. A concepção que prevaleceu sobre o que é avaliação da aprendizagem foi a da verificação do desempenho, do que o aluno aprendeu, muitas vezes acompanhada pelas palavras "prova" e "nota", demonstrando a cultura que ainda está enraizada nas universidades: do aluno como ser passivo e do professor como transmissor do conhecimento.

A falta de uma disciplina relacionada à avaliação da aprendizagem ou à própria docência pode influenciar a concepção dos professores a esse respeito. As concepções identificadas também se revelam nos instrumentos avaliativos empregados. O instrumento citado como utilizado por todos os professores foi a prova, entretanto esse instrumento geralmente não é o único, está acompanhado por outros. E, embora alguns alunos estejam satisfeitos com os instrumentos de avaliação da aprendizagem, boa parte está descontente e gostaria de melhorias. 
Dessa forma, os resultados encontrados, ainda que não conclusivos, ampliaram a compreensão a respeito da visão dos professores e dos alunos sobre a avaliação e forneceram informações relevantes sobre o ensino no Curso de Nutrição dessa instituição. Com base nesses resultados, também é possível ressaltar a necessidade e a importância de não só ser repensado constantemente o significado da avaliação da aprendizagem, mas também de capacitar continuamente professores e gestores do ensino superior, para que a avaliação realmente contribua para construção do conhecimento.

\section{REFERÊNCIAS}

ABREU, M. C.; MASETTO, M. T. O professor universitário em aula: prática e princípios teóricos. 11. ed. São Paulo: MG Associados, 1997.

ALMEIDA, M. B.; PERON, L. D. C.; SILVA, R. D. Concepções de avaliação de professores e alunos da rede pública do Estado do Paraná. Estudos em Avaliação Educacional, v. 20, p. 389-410, 2009.

AUGUSTO, C. E. Avaliação da aprendizagem no curso de Física da Unicamp. Revista online Biblioteca Professor Joel Martins, v. 2, n. 2, p. 104-126, 2001.

BERBEL, N. A. N. et al. Avaliação da aprendizagem no ensino superior. Um projeto integrado de investigação através da metodologia da problematização. In: REUNIÃO ANUAL DA ANPED, 23., p. 1-6, 2000, Caxambu-MG. Anais... Anped: Caxambu, 2000.

BRASIL. Ministério da Educação. Lei de diretrizes e bases, n. 9394, de 20 de dezembro de 1996. Estabelece as diretrizes e bases da educação nacional. São Paulo: Abril, 1997.

CAMARGO, A. L. C. O discurso sobre a avaliação escolar do ponto de vista do aluno. 1996. Tese (Doutorado em Educação) - Faculdade de Educação, Universidade Estadual de Campinas, Campinas, 1996.

CASAGRANDE, A.; MACEDO, C. G.; MACHADO, F. J. Urbanização de Florianópolis em fins do século XIX e início do século XX. 149 p. (Relatório de Estágio, Curso de História) - Udesc, Florianópolis, 2006.

COLLINS, J. Education techniques for lifelong learning: principles of adult learning. Radiographics, v. 24, n. 5, p. 1483-1489, 2004.

FALCÃO FILHO, J. L. M. A avaliação dos avaliadores. Ensaio, Avaliação e Políticas Públicas em Educação, Rio de Janeiro, v. 3, n. 6, p. 73-78, 1995.

FARIA, W. R. A Importância da avaliação no processo de ensino-aprendizagem aplicado no ensino superior. 2011. Disponível em: <http://www.administradores. com.br>. Acesso em: 7 maio 2011. 
FURLAN, M. I. C. Avaliação da Aprendizagem escolar: convergências e divergências entre os atores do processo de uma escola pública de ensino médio. 2006. 80p. Dissertação (Mestrado em Educação). Universidade do Oeste Paulista, Presidente Prudente, SP, 2006.

GARCIA, J. Avaliação e aprendizagem na educação superior. Estudos em Avaliação Educacional, v. 20, n. 43, p. 201-213, 2009.

GODOY, A. S. Avaliação da aprendizagem no ensino superior: estudo da arte. Didática, v. 30, p. 9-25, 1995.

GOMES, A. J. P.; ORTEGA, L. M.; OLIVEIRA, D. G. Dificuldades da avaliação em um curso de farmácia. Avaliação, v. 15, n. 3, p. 203-221, 2010.

GONÇALVES, M. L. Avaliação das aprendizagens por competências: instrumentos e práticas. 2008. 96 f. Monografia (Bacharelado em Ciências da Educação e Práxis Educativa) - Universidade Jean Piaget de Cabo Verde, Cabo Verde, 2008.

GRIGOLI, J. A. G. A sala de aula universitária na ótica do aluno: um estudo sobre a prática pedagógica na universidade. 1990. Tese (Doutorado em Educação) Pontifícia Universidade Católica de São Paulo, São Paulo, 1990.

HOFMANN, J. Avaliação mitos e desafio: uma perspectiva construtivista. Porto Alegre: Mediação, 1991.

LINN, R. L. Educational Measurement. Phoenix, AZ: American Council on Education/Oryz, 1993.

LUCKESI, C. C. Avaliação da aprendizagem escolar. 14. ed. São Paulo: Cortez, 2002.

MASETTO, M. T. Atividades pedagógicas no cotidiano da sala de aula universitária: reflexões e sugestões práticas. In: CASTANHO, S.; CASTANHO, M. E. Temas e textos em metodologia do ensino superior. 2. ed. Campinas: Papirus, 2001.

MINAYO, M. C. S. Fase do Trabalho de Campo. In: . Desafio do conhecimento: pesquisa qualitativa em saúde. Rio de Janeiro: Fiocruz, 1992.

PERRENOUD, P. Avaliação da excelência à regulação das aprendizagens. Porto Alegre: Artmed, 1999.

ROZENDO, C. A. et al. Uma análise das práticas docentes de professores universitários da área de saúde. Revista Latino-Americana de Enfermagem, v. 7, n. 2, p. 15-23, 1999.

SOUZA, C. P. Avaliação escolar: limites e possibilidades. Idéias, n. 22, p. 89-90, 1994.

VASCONCELLOS, C. S. Avaliação da aprendizagem: práticas de mudança por uma práxis transformadora. São Paulo: Libertad, 1998. 


\section{KÉLIN SCHWARZ}

Doutoranda em Ciências (Energia Nuclear na Agricultura

e no Ambiente) pela Universidade de São Paulo (USP).

Mestre em Agronomia, nutricionista. Especialista em Docência no ensino superior

kelinschwarz@hotmail.com

\section{PRISCILLA CAMPIOLO MANESCO PAIXÃO}

Historiadora, mestre em História. Professora titular do Centro Universitário de Maringá (Cesumar)

priscillapaixao@cesumar.br 


\section{ANEXO I}

\section{QUESTIONÁRIO (PROFESSOR)}

NÚMERO DO QUESTIONÁRIO

1. Formação profissional

( ) Ensino superior Área de formação:

( ) Especialização ( ) Mestrado ( ) Doutorado

( ) Outros

2. Idade:

( ) entre 20 e 25 anos ( ) entre 25 e 30 anos ( ) entre 30 e 40 anos

( ) mais de 40 anos

3. Sexo: ( ) F ( ) M

4. Nome da(s) disciplina(s) que ministra:

5. Há quanto tempo ministra aulas para o ensino superior?

( ) menos de 1 ano

( ) entre 1 e 5 anos

( ) entre 5 e 10 anos

6. E nesta instituição atual?
( ) menos de 1 ano
( ) entre 10 e 15 anos
( ) entre 1 e 5 anos
( ) entre 15 e 20 anos
( ) entre 5 e 10 anos
( ) mais de 20 anos

7. Explique o que você entende por avaliação da aprendizagem.

8. Cite quais são os instrumentos avaliativos que utiliza.

9. Explique que atitude você toma diante dos resultados das avaliações de seus alunos.

10. Relate se durante a realização de seu curso superior ou de sua pós-graduação você teve alguma disciplina relacionada à avaliação da aprendizagem.

a) No caso de resposta positiva à questão acima, relate se você julga que tal disciplina influenciou sua prática positivamente.

b) Em caso de resposta negativa à questão acima, explique como você aprendeu a avaliar. 


\section{ANEXO II}

\section{QUESTIONÁRIO (ALUNO)}

NÚMERO DO QUESTIONÁRIO

1. Idade:

( ) entre 17 e 20 anos ( ) entre 20 e 25 anos ( ) entre 25 e 30 anos
( ) entre 30 e 40 anos ( ) mais de 40 anos

2. Sexo: () F ( ) M

3. Explique o que você entende por avaliação da aprendizagem.

4. Cite os instrumentos avaliativos mais utilizados por seus professores.

5. Você considera eficientes para sua aprendizagem os métodos e instrumentos de avaliação utilizados por seus professores? Justifique sua resposta.

6. Que atitudes os professores tomam diante dos resultados das avaliações?

7. Descreva como você gostaria de ser avaliado. 